\title{
Mathematical Approaches to the Structural Analysis and Formalization of Woven Fabrics
}

\author{
Askarali Daminov, Otabek Kasimov \\ Tashkent Institute of Textile and Light, Tashkent, Uzbekistan \\ Email: askaralid@yahoo.com, otabekkasimov@gmail.com
}

How to cite this paper: Daminov, A. and Kasimov, O. (2016) Mathematical Approaches to the Structural Analysis and Formalization of Woven Fabrics. World Journal of Engineering and Technology, 4, 263-269. http://dx.doi.org/10.4236/wjet.2016.43D032

Received: October 11, 2016

Accepted: October 22, 2016

Published: October 29, 2016

\begin{abstract}
The present paper shows the mathematical approach of formalization of textile fabrics, based on concepts and elements of graph theory and the structural analysis of woven structures and possibility of numerical evaluation of interlacing factor of warp and weft threads in woven structures through the weight of a structural graph vertex. Research observes quantitative aspect of structural evaluation of threads topology in fabric focusing in graph theory, in order to present an application productivity of this theory to solve the technological tasks.
\end{abstract}

\section{Keywords}

Textile, Weaving, Structure, Plain Weave, Twill Weave, Rapport, Warp,

Weft Topology, Graph Theory, Vertex, Valency, Edge

\section{Introduction}

Contemporary textile science and technology, on the phase of raw material production for final product, particularly during the structural design of any fabrics, is using such chapters of mathematics as topology [1], theories of knots and braids [2] [3], objectoriented programming [4], which makes an industry knowledge-consumptive and a product more competitive.

In previous research [5], we studied the fundamentals of graph theory and their application to weaving technology as an instrument of mathematical formalization of woven structures, which pushed to further attempts.

The present study shows a possibility of numerical evaluation of interlacing factor of warp and weft threads in woven structures through the weight of a structural graph vertex, as a sum ratio. 


\section{Methods}

In any graph of weave structure the existence of four vertices with a valency equals 2 , is necessary. In a particular case of plain weave these four vertices with a degree of 2 is a full set of vertices existed in graph. But in general, when $R_{o}$ and $R_{y}$ are random, the number of such vertices from a set of all vertices of graph equals 4 . In total sum of degree of vertices, these 4 vertices give $4 \times 2=8$ valencies.

Graph of weave structure has also vertices with valency 3, located on the perimeter of rapport, excluding angular, such vertices as $v_{2}, v_{4}, v_{6}$, и, $v_{8}$ of twill weave 1/2 (Figure 1).

Their total number is equal to $2\left(R_{o}-2+R_{y}-2\right)$, and a share of similar vertices in total sum of valencies equals $3 \times 2\left(R_{o}-2+R_{y}-2\right)=6\left(R_{o}+R_{y}-4\right)$. And, finally, in general case of weave structure graph has vertices with valency 4 , located inside the rapport, for example vertex $v_{5}$ of graph of twill weave 1/2 (Figure 1). Their number equals $\left(R_{o}-2\right) \times\left(R_{y}-2\right)$ with share in total sum of vertices valencies $4\left(R_{o}-2\right) \times\left(R_{y}-\right.$ 2).

Thus, the sum of valencies of all vertices of fabric strcutural graph with random weave will be:

$$
\sum_{i, j=1}^{R_{o}, R_{y}} d\left(v_{i j}\right)=8+6\left(R_{o}+R_{y}-4\right)+4\left(R_{o}-2\right)\left(R_{y}-2\right)
$$

The desirable dependency for determination of the sum of valencies of graph vertices, comparable to any rapport of weave structure of one-layer fabrics at random values of $R_{o}$ and $R_{y}$ :

$$
\sum_{i, j=1}^{R_{o}, R_{y}} d\left(v_{i j}\right)=2\left(2 R_{o} R_{y}-R_{o}-R_{y}\right)
$$

And, the number of edges of any weave structure equals: $2 R_{o} R_{y}-R_{o}-R_{y}$

It is obvious, that structural graph of a fabric with a random weave can also be presented as a cycle. In particular case of plain weave with $R_{o}=R_{y}=2$, it poses a cycle as a sequence $v_{1}, e_{1}, v_{2}, e_{3}, v_{4}, e_{4}, v_{3}, e_{2}, v_{1}$. This is a very simple case with minimum number of cycles-1 cycle. As rapport increases, the number of cycles also gradually does. In above considered case of twill weave $1 / 2$ with $R_{o}=R_{y}=3$, already 4 cycles are being
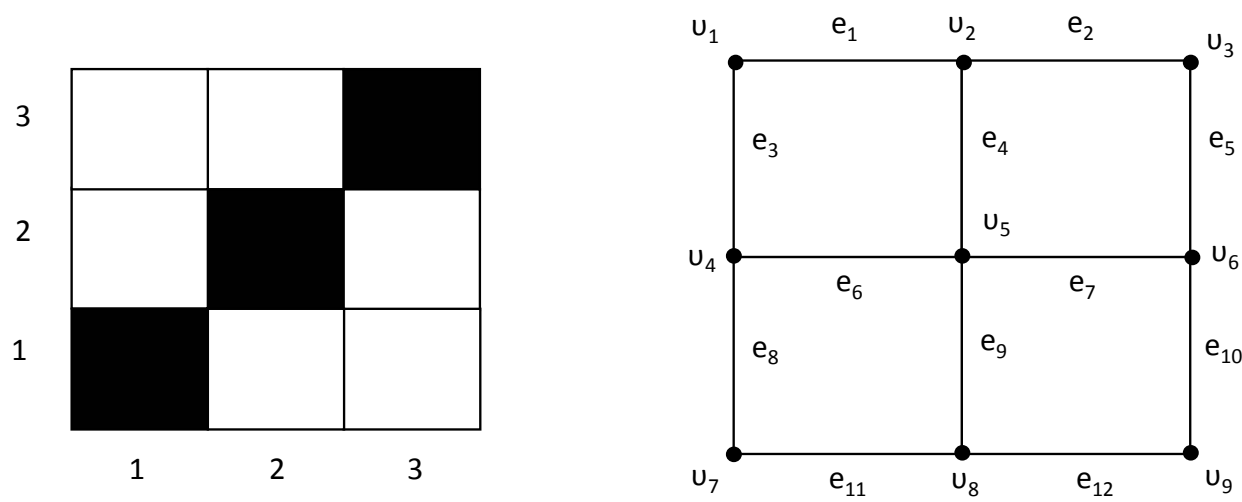

Figure 1. Twill weave 1/2 and its graph. 
formed: 1) $v_{1}, e_{1}, v_{2}, e_{4}, v_{5}, e_{6}, v_{4}, e_{3}, v_{1}$; 2) $\left.v_{2}, e_{2}, v_{3}, e_{5}, v_{6}, e_{7}, v_{5}, e_{4}, v_{2} ; 3\right) v_{4}, e_{6}, v_{5}, e_{9}, v_{8}$, $\left.e_{11}, v_{7}, e_{8}, v_{4} ; 4\right) v_{5}, e_{7}, v_{6}, e_{10}, v_{9}, e_{12}, v_{8}, e_{9}, v_{5}$.

Obviously, number of $R_{o}$ warp threads are forming vertical row of cycles $R_{o}-1$, number of $R_{y}$ weft threads, -horizontal row of cycles $R_{y}-1$. Thus, by defining the number of cycles of structural fabric graph of a random weave, at any $R_{o}$ and $R_{y}$ and not necessary that $R_{o}=R_{y}$ through $t_{s}$ can be:

$$
t_{s}=\left(R_{o}-1\right)\left(R_{y}-1\right)
$$

Let us observe quantitative aspect of structural evaluation of threads topology in fabric focusing in graph theory, in order to present an application productivity of this theory to solve the technological tasks. But this problem is linked to familiarization with some theses of graph theory, especially with concepts of edge and vertex coloring [6], the weight of edge and vertex and etc.

Edge $k$-coloring of graph is giving $k$ different colors to graph edges. And respectively, vertex $k$-coloring is giving $k$ different colors to its vertices.

Let us consequently define the number of colors for edges and vertices, comparable to weave structures. We form necessary logical reasoning as follows. Edges pose an area of warp and weft threads between single weaves, and vertices-weaves by themselves. Edge coloring is close linked with giving them of so called weight, which characterizes connectivity of adjacent pair of its vertices. Certain weight can also be given to the vertices. In this case, it also characterizes connectivity of edges incidental to this vertex. Therefore, edge and vertex coloring results splitting of a set of vertices $V$ and a set of edges $E$ of graph $G=(V, E)$, to independent subsets, the number of which is desirable number of k-colors necessary for edge and vertex coloring.

Starting with edges, which in population generate the set $E$, and number of elements equals to half of sum of graph vertices valency. Then, we divide a set $E$ to independent subsets according to the weight of edges. In context of the task on defining of quantitative criterias of threads interlacing evaluation, there can be two cases. Actually, the edge of a graph can link a couple of vertices, to which it is incidental, by one of two variants graphically illustrated in Figure 2.

It is clear that the link quality of adjacent vertices incidental to pending edge, is to be defined exactly by the weight of this edge, if take quantitative identification of two variants shown in figures. Edges of first variant imitating direct area of fabric and linking couples of adjacent vertices $v_{6}-v_{9}$ or $v_{8}-v_{9}$ (Figure 1 ) have 0 weight, because existence of such edges in a graph do not strengthen link of graph vertices, or technologically-the solidity of woven structure. Edges of the second variant, on the contrary, by imitating crossing from outside to inside of fabric or vice versa, strengthen link of graph vertices and lead to increase of interlacing of threads in fabric, and consequently have the weight 1 . Such edges linking couples of adjacent vertices $v_{3}-v_{6}$ or $v_{7}-v_{8}$ are shown in Figure 1. Whole rapport area of weave structure consists of only these two variants of threads area, which form a set $E$ of structural graph of fabric. Therefore, a set $E$ can be divided to two subsets $E_{0}$ and $E_{1}$ with elements of edges and weight values 

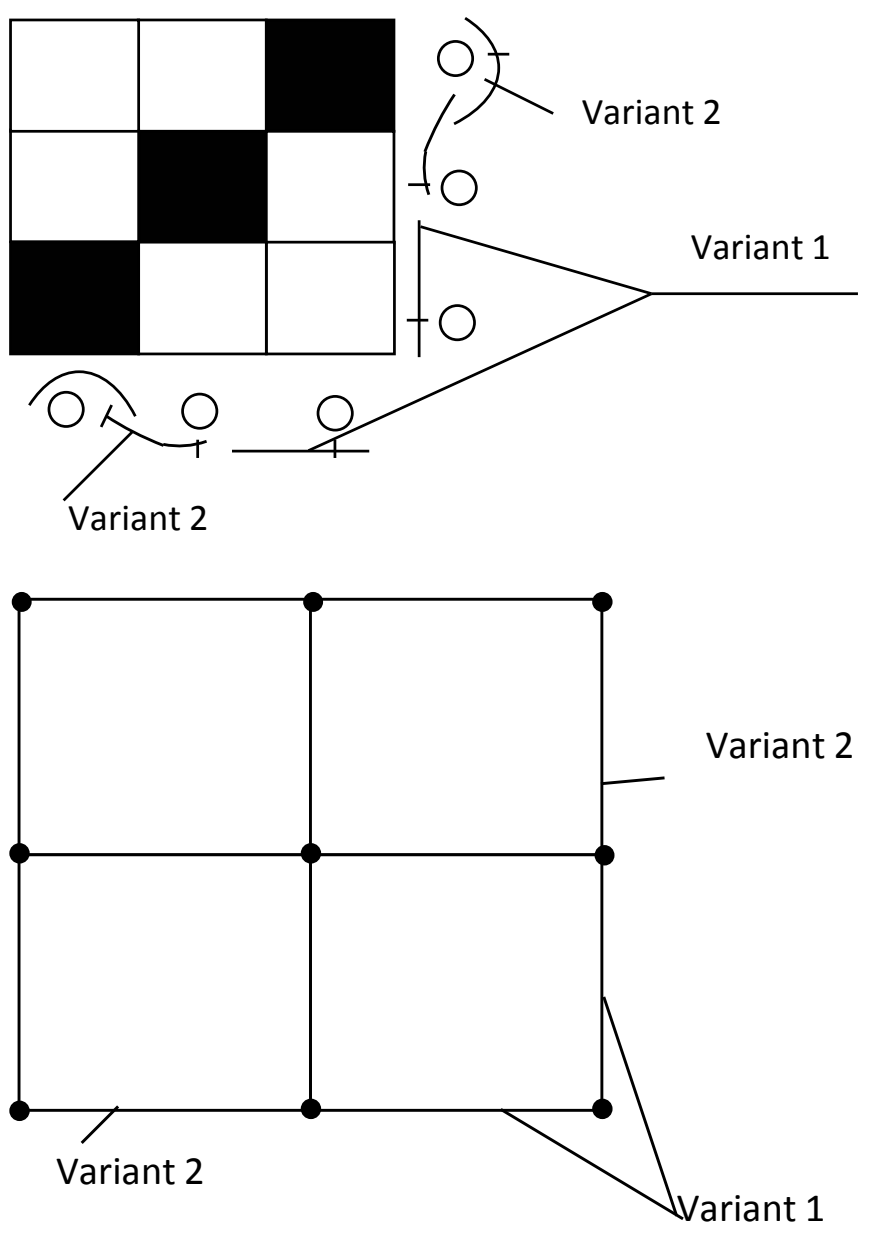

0

1

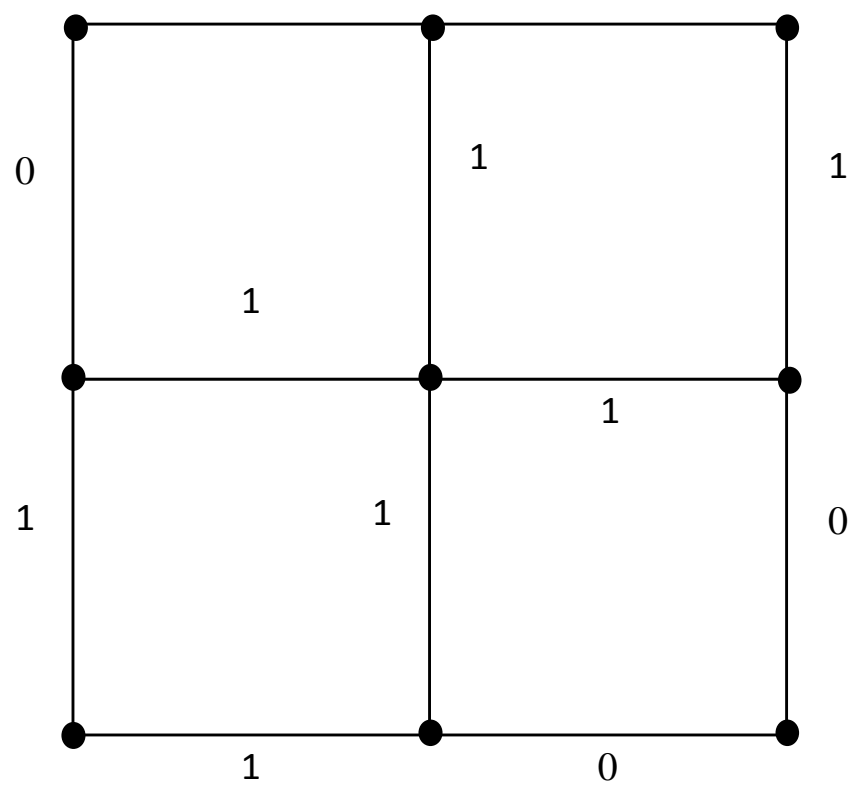

Figure 2. Weight defining of edges of structural graph of fabric. 
equal to 0 and 1 respectively. These two subsets define the number of colors necessary to color all edges of structural graph of fabric.

For instance, structural graph of twill fabric 1/2, shown in Figure 1, consisting of a set of edges $E=\left(e_{1}, e_{2}, \ldots, e_{12}\right)$, is being divided to two subsets:

$E_{0}=\left(e_{1}, e_{3}, e_{10}, e_{12}\right)$ with weight 0 , and

$E_{1}=\left(e_{2}, e_{4}, e_{5}, e_{6}, e_{7}, e_{8}, e_{9}, e_{11}\right)$ with weight 1 .

Same as edges, a universe of graph vertices with numerosity $R_{o} \times R_{y}$ forms a set $V$, which also can be divided to a range of independent subsets by the weight of vertices characterizing connectivity of incidental edges of random vertex. Let us define a variety of vertex weights, which defines a number of independent subsets $V$ and poses a number of $k$ colors to vertex coloring of any ctructural graph of fabric.

\section{Results}

As marked above, in general approach, any vertex of structural graph of fabric is incidental to four edges, i.e. has 4 valencies (Figure 3). And each edge has its weight. Denote by $k^{I}, k^{I I}, k^{I I I}, k^{I V}$-weights of edges incidental to pending vertex. And, same as in previous paragraph, here we stick on topographical order of orientation on a plane: Roman numerals I, II, III, IV consequently reflect weights of vertex edges, starting from "northern", then clockwise- “eastern", "southern" and "western". According to combination of weights of four edges, the weight of vertex will also change. But variety of weights of vertices is limited. In order to determine their number, we group all vertices by sum of edge weights, which have numerical values:

$$
k^{I} ; k^{I I} ; k^{I I I} ; k^{I V}=\left\{\begin{array}{l}
0, \text { if adjacent vertices do not intersect; } \\
1, \text { if intersection does exist. }
\end{array}\right.
$$

Then, for a random vertex of structural graph of a fabric on intersection of $i$-row and j-column (Figure 4), desired sum can be:

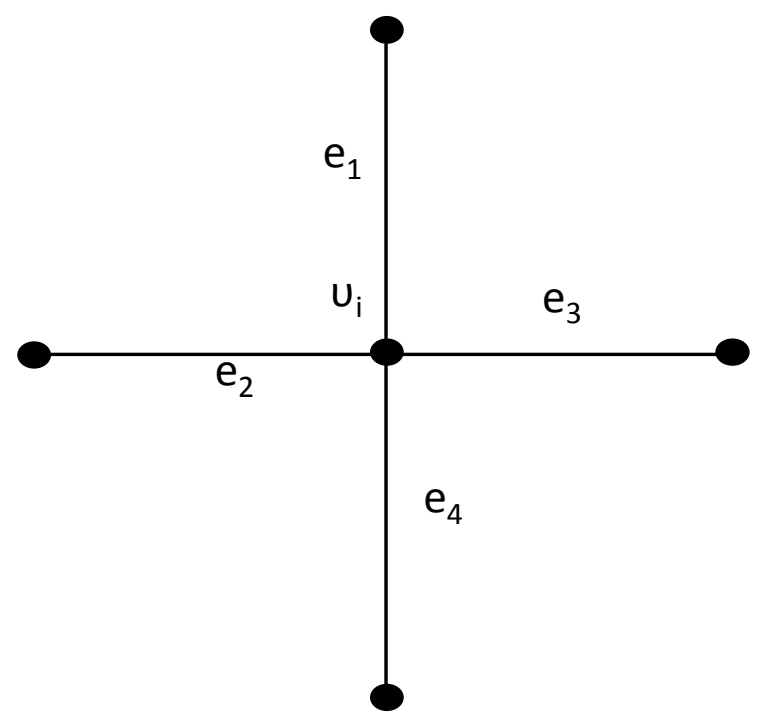

Figure 3. Minimal structutral unit of the structural graph of the fabric with random weave. 
1

2

3

j $\quad$ j

$\cdots$

m

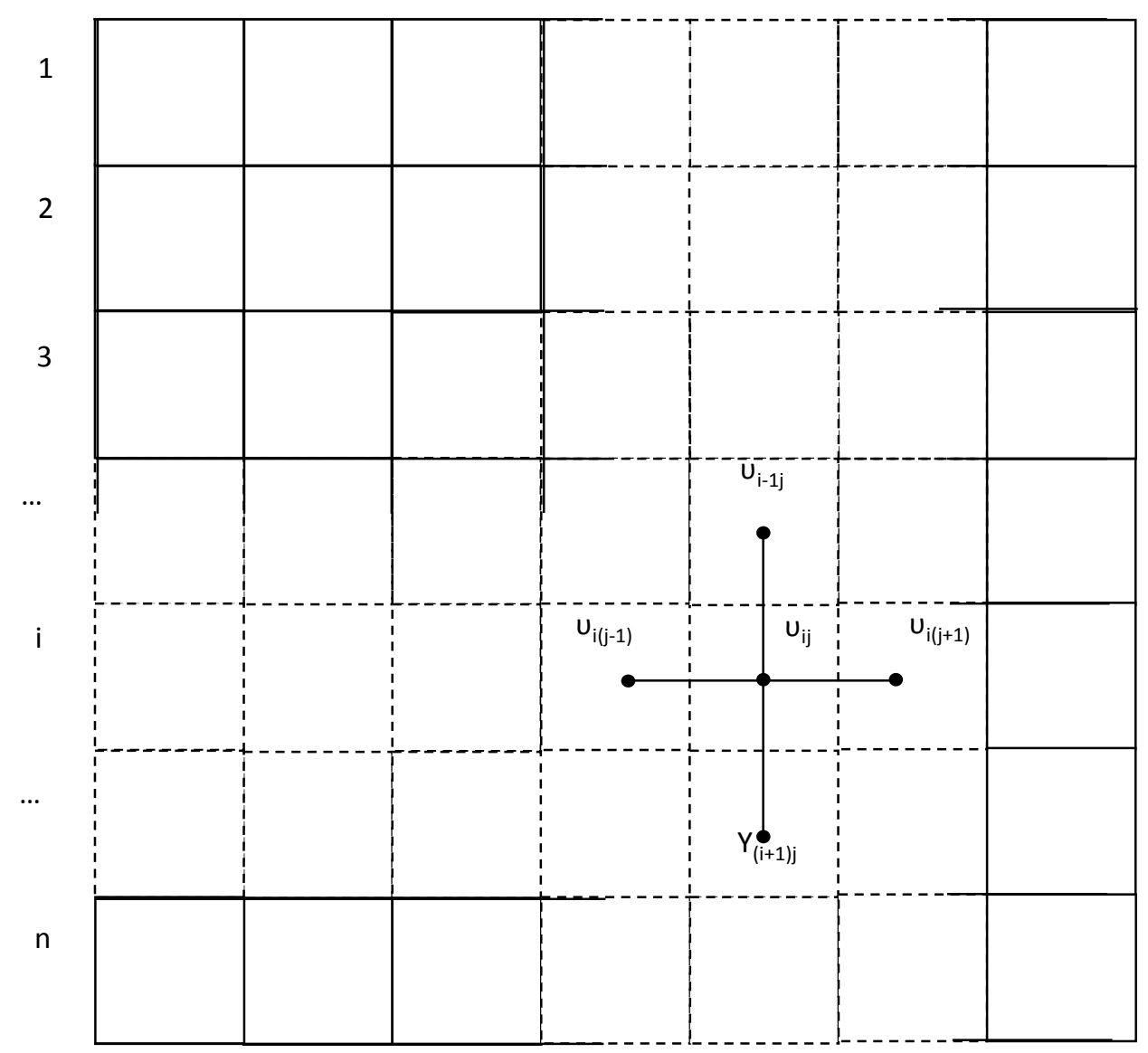

Figure 4. Unlimited rapport area of weave structure.

$$
k_{i j}^{I}+k_{i j}^{I I}+k_{i j}^{I I I}+k_{i j}^{I V}=\left\{\begin{array}{l}
0, \text { when all edges of a graph have the weight } 0 ; \\
1, \text { when any of } 4 \text { edges has the weight } 1 ; \\
2, \text { when } 2 \text { of } 4 \text { edges have the weight } 1 ; \\
3, \text { when } 3 \text { of } 4 \text { edges have the weight } 1 ; \\
4, \text { when all } 4 \text { edges have the weight } 1 .
\end{array}\right.
$$

Therefore, the number of colors of structural graph of random single-texture fabric equals 5 .

But, then colors for vertex coloring should be chosen, i.e. to assign absolute numbers to vertices, denoting them $s$. And here as well, we will lean on the sum of edge weights, formed by all 4 incidental edges of vertex together. By dividing the sum of weights of incidental edges to their number, i.e. to 4 , we will get colors:

$$
s_{i j}=\left(k_{i j}^{I}+k_{i j}^{I I}+k_{i j}^{I I I}+k_{i j}^{I V}\right) \frac{1}{4}=\left\{\begin{array}{l}
0, \text { when all edges of graph have the weight } 0 ; \\
0,25, \text { when } 1 \text { of edges has the weight } 1 ; \\
0,75, \text { when } 3 \text { edges have the weight } 1 ; \\
0,75, \text { when } 3 \text { edges have the weight } 1 ; \\
1, \text { when all } 4 \text { edges have the weight } 1 .
\end{array}\right.
$$


Thus, the whole rapport area of a specified fabric, formalized as a graph, can be colored to $0 ; 0.25 ; 0.5 ; 0.75$ and 1 colors. That means nothing else than comparison of the matrix-rapport with a dimensionality equal to $R_{o} \times R_{y}$ which consists exactly of these 5 elements, to the rapport of weave structure.

\section{Conclusion}

Summarizing present article we can conclude that a lot of concepts and elements of mathematical theory of topology are closely approximated to the textile technology. In the other hand, textile objects also have their internal topological setting, conditioned by mutual spatial arrangement of their elements. Therefore, elements of topology can be used as instruments of mathematical formalization of structure and technology of textile fabrics.

\section{References}

[1] Даминов, А.Д. (2005) Основы прогнозирования структуры и проектирования текстильных полотен. D.Sc. Thesis, Tashkent Institute of Textile and Light Industry, Tashkent. (In Russian)

[2] Manturov, V.O. (2005) Knottheory. Regulyarnaya i khaoticheskayadinamika, Moscow, Izhevsk. (In Russian)

[3] Мантуров, В.О. (2004) Экскурс в теорию кос и узлов. Соросовский образовательный журнал, том 8, № 1. (In Russian)

[4] Адаменко, A.Н. (2005) Pascal на примерах из математики. СПб.: БХВ-П етербург. (In Russian)

[5] Kasimov, O. (2015) Basic Concepts of Graph Theory as the Instruments of Mathematical Formalization of Woven Structures. World Journal of Engineering and Technology, 3, 344347.

[6] Lewis, R.M.R. (2016) A Guide to Graph Colouring. Algorithms and Applications. Springer International Publishing.

Submit or recommend next manuscript to SCIRP and we will provide best service for you:

Accepting pre-submission inquiries through Email, Facebook, LinkedIn, Twitter, etc.

A wide selection of journals (inclusive of 9 subjects, more than 200 journals)

Providing 24-hour high-quality service

User-friendly online submission system

Fair and swift peer-review system

Efficient typesetting and proofreading procedure

Display of the result of downloads and visits, as well as the number of cited articles

Maximum dissemination of your research work

Submit your manuscript at: http://papersubmission.scirp.org/

Or contact wjet@scirp.org 